\title{
Characterization of cis-acting elements in the rat ATP citrate- lyase gene promoter
}

\author{
Young-Ah Moon ${ }^{1}$, Sahng-Wook Park ${ }^{2}$ and \\ Kyung-Sup Kim ${ }^{3,4}$ \\ ${ }^{1}$ Department of Biochemistry \& Molecular Biology, Institute of \\ Genetic Science, Yonsei University College of Medicine, Seoul \\ 120-752, Korea \\ ${ }^{2}$ Department of Biochemistry, Kwandong University College of Med- \\ icine, Kangnung 210-701, Korea \\ ${ }^{3}$ Brain Korea 21 project for Medical Science of Yonsei University \\ ${ }^{4}$ Corresponding author: Tel, +82-2-361-5184; \\ Fax, +82-2-312-5041; E-mail, kyungsup59@yumc.yonsei.ac.kr
}

Accepted 27 February 2002

Abbreviations: ACL, ATP-citrate lyase; Sp1, specificity protein 1; C/ EBP, CAAT-enhancer-binding protein; CAT, chloramphenicol acetyltransferase.

\begin{abstract}
The cis-acting element in the promoter of the rat ATPcitrate lyase $(A C L)$ and transcription factors which interact with these elements were determined. Six Sp1 binding sites and CAAT box exist in the region from transcription start site to -419 bp which showed the highest promoter activity in ACL promoter previously. In the region from -612 to -419 , C/EBP binding site and other protein binding sites were also detected. Chloramphenicol acetyltransferase assay of $\mathrm{ACL}$ promoter suggested that multiple Sp1 sites might be involved in the ACL transcription. Gel mobility shift assay with antibodies against $\mathrm{Sp} 1$ and $\mathrm{Sp} 3$ revealed that DNA binding efficiency of Sp1 is increased in the liver of rats re-fed low fat/high carbohydrate diet after fasting. These results suggest that Sp1 is one of the most important transcription factors for ACL promoter to produce basal and induced transcription by low fat/high carbohydrate diet.
\end{abstract}

Keywords: ATP citrate-lyase promoter, Sp1, C/EBP, NF-Y, lipogenesis

\section{Introduction}

ATP-citrate lyase (ACL) is an enzyme that mediates the conversion of citrate to oxaloacetate and acetyl CoA in cytosol (Kornacker and Lowenstein, 1965). The acetyl
CoA produced by $A C L$ is used in the synthesis of fatty acid and cholesterol, so ACL is considered as one of the lipogenic enzymes like fatty acid synthase, acetyl CoA carboxylase, or malic enzyme. ACL activity is regulated by diet, that is, the activity of ACL is increased by fat free/high carbohydrate diet after fasting (Kim et al., 1992a). The increase of ACL activity is due to the increase of $A C L$ transcription rate in nuclei, followed by increase in $A C L$ enzyme synthesis. We previously reported the exon-intron organization of rat $A C L$ gene including the sequence of promoter region and its promoter activity (Kim et al., 1994; Moon et al., 1996). In ACL promoter, the region from transcription initiation site to -419 showed the highest promoter activity in $\mathrm{CHO}$ cells, HepG2 cells and primarily cultured rat hepatocytes (Kim et al., 1996). In human ACL promoter, the cluster of Sp1 binding sites was reported to mediate glucose-responsive induction of ACL gene (Moon et al., 1999). The region between -114 to -60 in rat $A C L$ promoter was also postulated to play a central role in induction by SREBP1, which is known to mediate the induction of several lipogenic enzymes (Moon et al., 2000). These previous studies suggested that the proximal promoter region, from -419 to transcription start site, is the most important region for the promoter activity of ACL. In this study, we determined the cisacting element and transcription factors interact with these DNA sequences in the region from -624 to +128 of the rat $A C L$ gene. We also proposed their roles for the induction of ACL transcription in refeeding state.

\section{Materials and Methods}

\section{Preparation of nuclear extracts}

Sprague Dawley rats (about $200 \mathrm{~g}$ ) were divided into three groups. First group was fed normal diet, the second group was fasted for $48 \mathrm{~h}$, and the third group was fasted for $48 \mathrm{~h}$, then refed fat free/high carbohydrate diet for $12 \mathrm{~h}$. Nuclear extracts were prepared from the livers of those groups according to the method described by Gorski et al. (1986). Protein concentrations of nuclear extracts were determined by the method of Bradford (1976). Nuclear extracts were divided into aliquots and stored at $-70^{\circ} \mathrm{C}$.

\section{DNase I footprinting}

DNA fragments covering the region from $-625 \mathrm{bp}$ to $-373 \mathrm{bp},-420 \mathrm{bp}$ to $-115 \mathrm{bp}$, and $-114 \mathrm{bp}$ to $+128 \mathrm{bp}$ were produced by restriction enzyme digestion of $A C L$ 
Table 1. Oligonucleotide sequences used in this experiment. The nucleotide sequences shown in this table are those of sense strand. Complementary antisense strands were also synthesized

\begin{tabular}{|c|c|c|c|}
\hline Name & Location & Sequence & Reference \\
\hline II & $-67 /-41$ & 5'-AGCTGATGGGGGGCGGGGAGGAGCCCG-3' & \\
\hline III & $-102 /-72$ & 5'-CGCGTGTGCCCAATCGCCAGGCTGCATGGCC-3' & \\
\hline IV & $-142 /-116$ & 5'-AGCAGCGAATGGGGAGGAGCCTAGAGC-3' & \\
\hline V & $-165 /-139$ & 5'-AGGCATGAGGGCGGGGCCACCGCAGCA-3' & \\
\hline VI & $-219 /-190$ & 5'-CCGGCCCACGGCCCCTCCCACTTCCAAGAC-3' & \\
\hline VII & $-252 /-226$ & 5'-CTAGAGCTGCCCCGCCCATCTCCCCAT-3' & \\
\hline VIII & $-349 /-325$ & 5'-CСAACAACССССТСССАСАGСТАCC-3' & \\
\hline IX & $-438 /-413$ & 5'-TACAAACGCCAGAGATAAGAACGTCA-3' & \\
\hline $\mathrm{X}$ & $-487 /-463$ & 5'-GACGTAGCTTTCCAAAGCAGGTCTA-3' & \\
\hline $\mathrm{XI}$ & $-515 /-488$ & 5'-GAGAGGCGCCACGTGTGAAAGGAAAGCA-3' & \\
\hline Sp1 & & 5'-ATTCGATCGGGGCGGGGCGAGC-3' & Briggs et al., 1986 \\
\hline NF-Y & & 5'-GGGGTAGGAACCAATGAAATGAAAGGT-3' & Raymondjean et al., 1991 \\
\hline CTF/NF! & & 5'-CCTTTGGCATGCTGCCAATATG-3' & Chodosh et al., 1988 \\
\hline C/EBP & & 5'-AATTCAATTGGGCAATCAGGAATT-3' & Lemaigre et al., 1993 \\
\hline ChoRE & & 5'-TACTCTGTTTGCCAGTTCTCACGTGGTGGCCACGCGTA-3' & Shih and Towle, 1992 \\
\hline HNF-1 & & 5'-CTAGCTGGTTATACTTTAACCAGG-3' & Lemaigre et al., 1993 \\
\hline HNF-3 & & 5'-GTTGACTAAGTCAATAATCAGA-3' & Lemaigre et al., 1993 \\
\hline HNF-4 & & 5'-GCGCTGGGCAAAGGTCACCTGC-3' & Lemaigre et al., 1993 \\
\hline HNF-5 & & 5'-CTAGAACAAACAAGTCCTGCGT-3' & Lemaigre et al., 1993 \\
\hline
\end{tabular}

promoter clones, and then subcloned into the pGEM-4Z plasmid vector. These clones were digested with both EcoRI and Pstl or Hindlll and Sacl to produce DNA fragments having both $3^{\prime}$ overhang and 5 ' overhang end. To make a radio-labeled probe $5^{\prime}$ overhang end was labeled with $\left[\alpha^{32} \mathrm{P}\right] \mathrm{dATP}$ using Klenow enzyme. From 0 to $100 \mathrm{mg}$ of nuclear extracts were incubated with $50,000 \mathrm{cpm}$ of radio-labeled probes for $20 \mathrm{~min}$ on ice under the same condition of gel mobility shift assay, followed by treating DNase I (10 units/ $\mu$ l, Boehringer Mannheim, Germany) solution diluted from 1:200 to 1: 1000. The reaction was stopped by adding stop solution (20 mM Tris-Cl, pH 8.0, 20 mM EDTA, $250 \mathrm{mM} \mathrm{NaCl}$, $0.5 \%$ SDS, $10 \mu \mathrm{g}$ of proteinase $\mathrm{K}$ and $4 \mu \mathrm{g}$ of yeast tRNA) and incubated for $30 \mathrm{~min}$ at $45^{\circ} \mathrm{C}$. DNA was extracted with phenol/chloroform and precipitated. DNA was separated on $8 \mathrm{M}$ urea/6\% polyacrylamide gel. The locations of footprints were ascertained by comparing with $\mathrm{G}+\mathrm{A}$ ladder produced by chemical cleavage sequencing reactions of the same probe (Sambrook et al., 1989).

\section{Gel mobility shift assay}

The oligonucleotides used in gel mobility shift assay are listed in Table 1. The equal amounts of each complementary single stranded oligonucleotides were annealed to double stranded oligonucleotides in 0.5 X TE solution by heating $90^{\circ} \mathrm{C}$ for $10 \mathrm{~min}$ and then slowly cooling to room temperature. Double stranded oligonucleotides were labeled with $\left[\gamma_{-}{ }^{32} \mathrm{P}\right] \mathrm{ATP}$ using T4 polynucleotide kinase. Binding reaction was performed in the condition of $10 \mathrm{mM}$ HEPES, pH 7.9, $60 \mathrm{mM} \mathrm{KCl,} 1 \mathrm{mM}$ EDTA, 1 $\mathrm{mM}$ dithiothreitol, $7 \%$ glycerol, $2 \mu \mathrm{g}$ of poly $\mathrm{dl}-\mathrm{dC}$. $100,000 \mathrm{cpm}$ of labeled oligonucleotide and $10 \mu \mathrm{g}$ of nuclear extract were used for each reaction. The reaction mixture was incubated on ice for $20 \mathrm{~min}$ and then separated on the $0.25 \times \mathrm{TBE}, 5 \%$ glycerol, $5 \%$ polyacrylamide gel at $300 \mathrm{~V}$ for approximately $1 \mathrm{~h}$ at $4^{\circ} \mathrm{C}$. For competition assay, 100 fold molar excess amount of unlabeled oligonucleotides were added to the binding reaction. For supershift assay, $1 \mu \mathrm{l}$ of polyclonal antibodies against Sp1 and Sp3 (Santa Cruz Biotechnology) were added to the binding reaction.

\section{Construction of ACL promoter-chloramphenicol acetyl- transferase (CAT) plasmids}

pNP82-CAT and pNP64-CAT were reported previously (Kim et al., 1996). p-264-CAT, p-218-CAT, p-170-CAT are deletion clones prepared from pNP64-CAT or pNP82CAT by using exonuclease III as described previously (Kim et al., 1996).

\section{Primary hepatocyte culture and transfection}

Hepatocytes isolated from a rat were cultured as described by Shih and Towle (1992). After 6 h-attachment period, transfections were performed in modified Williams E media (lacking glucose and methyl linoleate supplemented with $10 \mathrm{mM}$ lactate, $0.1 \mathrm{unit} / \mathrm{ml}$ insulin, $10 \mathrm{nM}$ dexamethasone) using Lipofectin reagent (GIBCO BRL, Gaithersburg MD). Cells were cultured for additional 48 $\mathrm{h}$ in the presence of $10 \mathrm{mM}$ lactate, then cells were harvested and CAT assay was carried out by thin layer 
chromatography (TLC) (Sambrook et al., 1989). TLC plate was exposed to imaging plate and signal intensities were counted by phosphoimager (BAS2500, Fuji Photo Film Co.). CAT activity was presented as \% conversion and was standardized by co-transfected $\beta$ galactosidase activity (Sambrook et al., 1989).

\section{Results}

Rat liver nuclear proteins protect several regions of rat $A C L$ gene promoter

We previously suggested that -419 nucleotide upstream from the start site of ACL promoter is the most important region for transcription (Kim et al., 1996). The possible regulatory elements in the region from -625 to +128 are investigated by DNase I footprinting using rat liver nuclear extract (Figure 1). Twelve regions were protected by binding of nuclear proteins, that is, $-582 /-562$ (PR XII), -511/-491 (PR XI), -481/-468 (PR X), -434/-417 (PR IX), -348/-324 (PR VIII), -250/-228 (PR VII), -216/-192 (PR VI), -162/-143 (PR V), -136/-118 (PR IV), -102/-72 (PR III), -62/-47 (PR II) and -20/+36 (PR I) (Figure 2, 3). $\mathrm{PR}$ II, V, and VII contain consensus sequence of Sp1 transcription factor binding site. PR IV, VI, and VIII contain GGGAGG, similar to Sp1 binding sequence, which Sp1 factor has been reported to be able to bind to in some promoters (Baker et al., 1996). The sequence of PR X was homologous to C/EBP binding site in inverse direction (Lemaigre et al., 1993) and the sequence of PR XI was homologous to that of E-box or carbohydrate response element (ChoRE) which was reported in the promoter region of S14 gene and L-type pyruvate kinase gene (Shih and Towle, 1992; Liu and Towle, 1995). The sequence of PR III was homologous to CCAAT box.

\section{Comparison the binding activity of transcription factors to DNA elements between the rats fasted 48 $h$ and rats refed high carbohydrate diet for $12 \mathrm{~h}$ after $48 \mathrm{~h}$ fasting}

The earlier study revealed that $A C L$ is regulated by diets

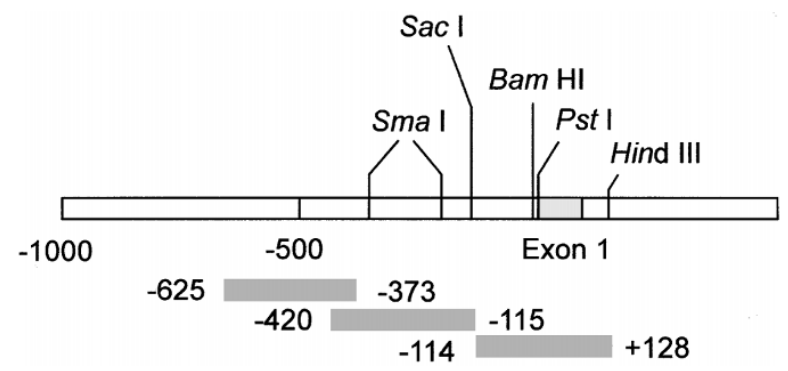

Figure 1. Promoter fragments for DNase I footprinting. DNA fragments covering the region from -625 bp to $-373 b p,-420$ bp to $-115 b p$, and -114 bp to +128 bp were produced by restriction enzyme digestion of $\mathrm{ACL}$ promoter clones, and then subcloned into the pGEM-4Z plasmid vector. at the transcription level (Kim et al., 1992). The transcriptional activity of $A C L$ gene in nuclei of rat liver began to increase at $4 \mathrm{~h}$ from refeeding high carbohydrate diet after fasting and further increased to reach a maximum level of 24 fold at $12 \mathrm{~h}$, maintaining a high level of 17 fold until $48 \mathrm{~h}$. To compare the changes of transcription factor bindings to the ACL promoter according to the nutritional state, the gel mobility shift assay were performed, using oligonucleotides, of which sequences were protected in DNase I footprinting assay, and hepatic nuclear extracts from fasted or refed rats. The protein binding to PR II, IV, V, VI, VII, VIII was increased by nuclear extract of rat refed high carbohydrate diet. Protein binding to box IX, X, XI seemed to be decreased in the case of induced rat (Figure 4).

The nuclear proteins that bind to the box II, IV, V, VI, VII, and VIII, are Sp1 family transcription factors

Protected regions II, IV, V, VI, VII, and VIII showed sequence homology to Sp1 binding site. To characterize the transcription factors that bind to the protected regions, we performed the gel mobility shift assay and competition assay (Figure 5). Radio-labeled oligonucleotides of protected regions were incubated with rat liver nuclear extract, which showed the formation of specific DNAprotein complexes. To identify the transcription factors, which involve the binding reaction, unlabeled oligonucleotides were added to the binding reaction. The shifted bands indicated with arrows were disappeared by the cold Sp1 oligonucleotide (Figure 5). To confirm whether the complex, disappeared by the cold Sp1 oligonucleotide, really contains the Sp1, supershift assay was performed using antibodies against Sp1 and Sp3 (Figure 6). In feeding state, PR II formed three major complexes indicated with arrows, while most slowly migrating complex was disappeared in fasting state. Antibody against Sp1 mainly supershifted upper two bands of complexes, while antibody against Sp3 diminished the lower two bands, suggesting that the most slowly or fast migrating complex contained Sp1 or Sp3, respectively and the middle one probably contains both of Sp1 and Sp3 in feeding state. These results demonstrated that $\mathrm{Sp} 1$ binding activities are most severely affected by feeding condition.

\section{NF-Y binds to CCAAT box of ACL}

The sequence of PR III was homologous to CAAT box sequence. A number of proteins, some of which are expressed in all tissues while others are expressed in a tissue specific manner, have been known to bind to CCAAT box (Rajmondjean et al., 1988). To identify the transcription factor that binds to the CAAT box in ACL promoter, gel mobility shift assay was done with competition. DNA-protein complex formation was not affected by addition of cold CTF/NF-1 or C/EBP binding 
A.

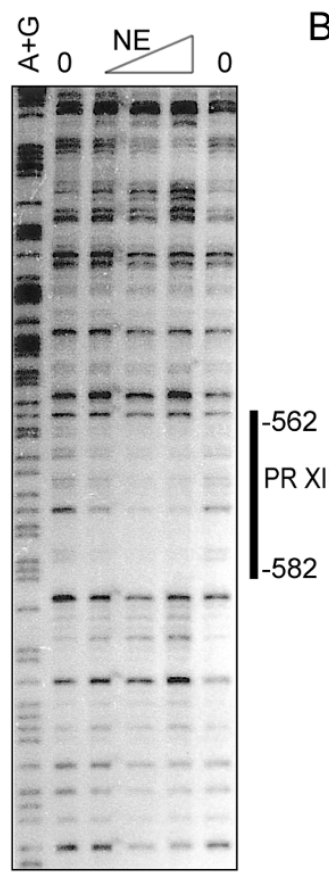

D.

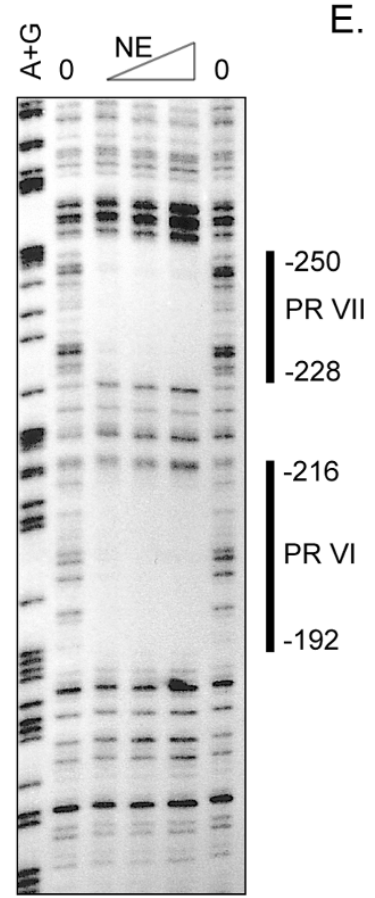

B.

E.
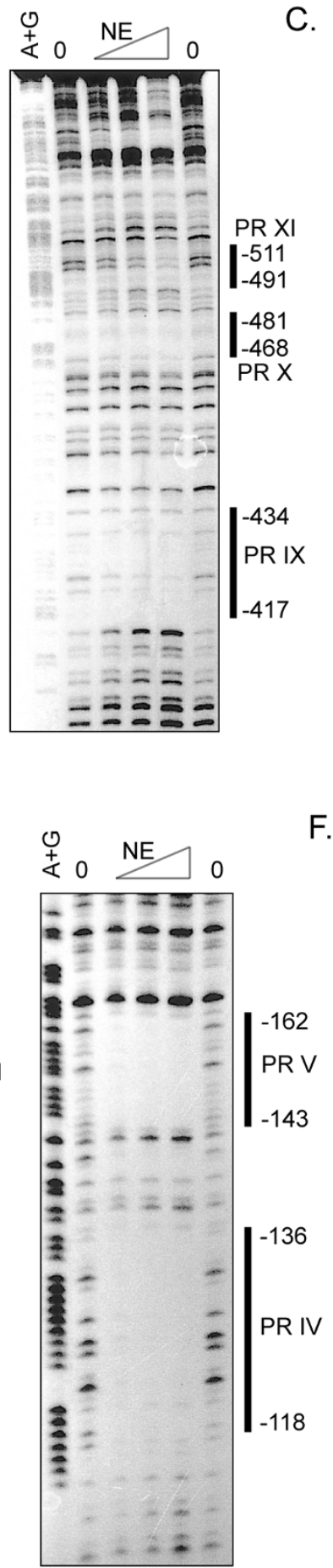

C.

F.
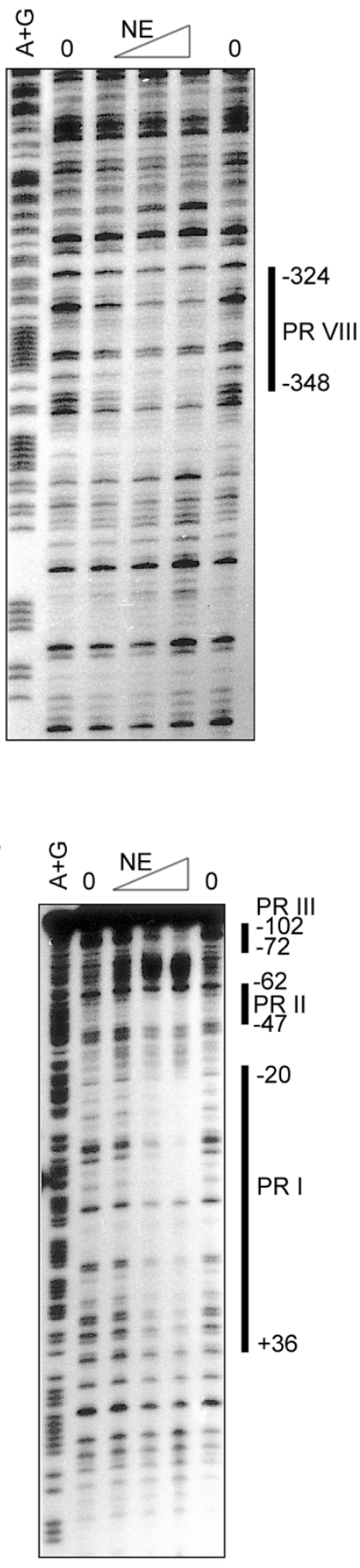

Figure 2. DNase I footprinting analysis of ACL promoter. DNA fragments covering the region from $-625 \mathrm{bp}$ to $-373 \mathrm{bp},-420 \mathrm{bp}$ to $-115 \mathrm{bp}$, and $-114 \mathrm{bp}$ to +128 bp were labeled by filling reaction with $\left[\alpha-{ }_{-}^{32}\right.$ P]dATP by Klenow enzyme. Labeled DNA fragments were incubated with increasing amounts of nuclear extracts prepared from rat liver and then treated with DNase I. The black lines are protected regions from DNase I. A+G means Maxam-Gilbert chemical sequencing ladder of same fragment.

sequence, while cold self and NF-Y binding sequence completely inhibited the complex formation (Figure 7A). And this complex was supershifted by anti-NF-Y antibody (data not shown). The above results indicated that the NF-Y is the major factor binding to PR III containing CCAAT box.

\section{Certain nuclear protein binds to PR IX}




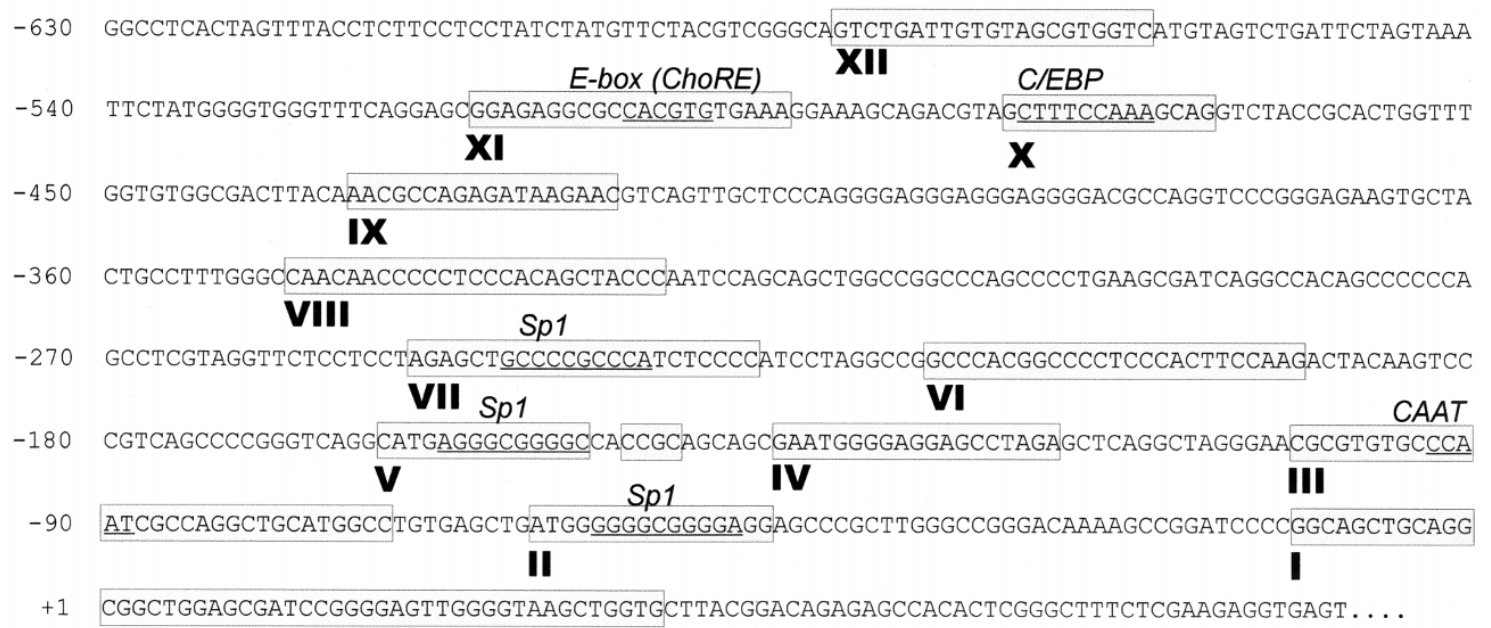

Figure 3. Nucleotide sequence of the ACL promoter and protein binding sites. The boxes are protected regions in DNase I footprinting assays. The consensus binding sequence of Sp1, C/EBP and ChoRE are indicated.
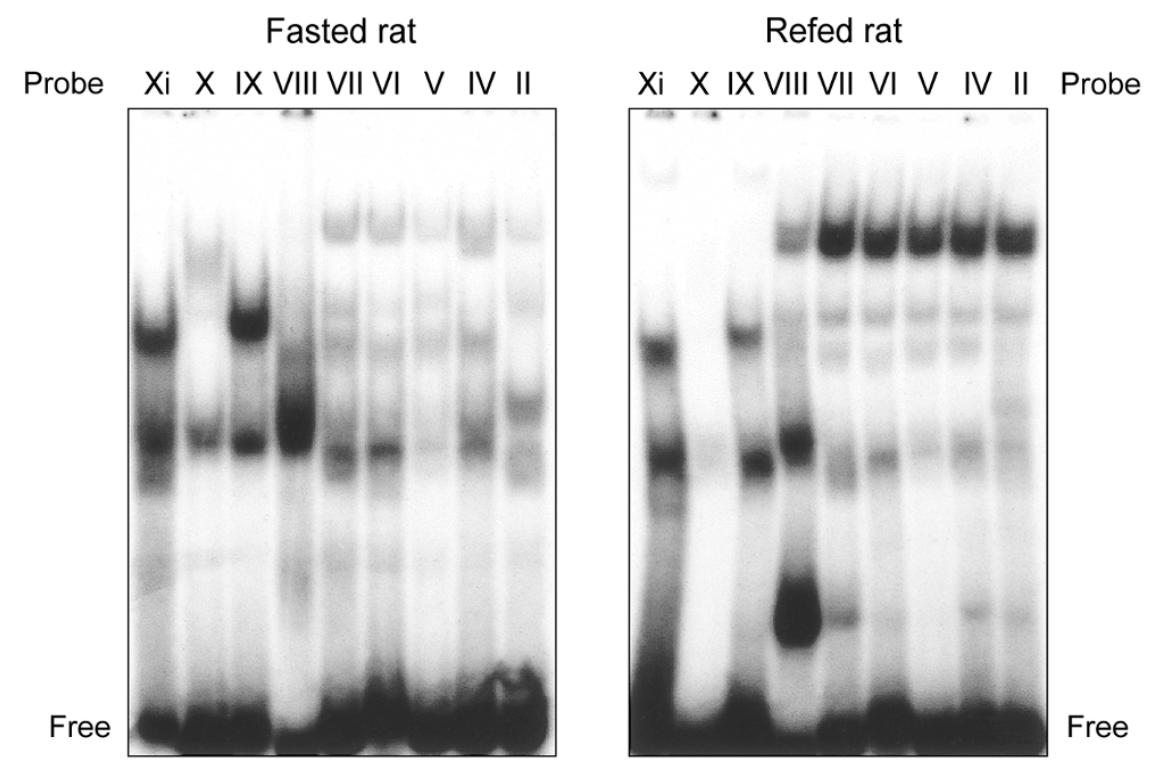

Figure 4. Protein binding activity in nuclear extracts prepared from rats fasted for $48 \mathrm{~h}$ or refed high carbohydrate/low fat diet for $12 \mathrm{~h}$ after $48 \mathrm{~h}$-fasting to oligonucleotides corresponding to protected regions in DNase I footprinting assay. The DNA-protein complexes were formed by incubation of each probe $(100,000$ c.p.m.) and $10 \mathrm{mg}$ of nuclear extract, and then separated in 5\% polyacrylamide gel as described in Materials and Methods. The protein concentrations of nuclear extracts were determined by Bradford method (1976) and were confirmed by quantitating the NF-Y-PR III complex formation.

The nucleotide sequence of PR IX didn't show similarity to any reported cis-acting elements. But when a radiolabeled fragment was mixed with nuclear extracts, the specific DNA-protein complex was observed. This complex was not competed out by other hepatic nuclear factors, for example HNF1, HNF3, HNF4, and HNF5 (Figure 7B).

\section{C/EBP binds to the PR $X$ of ACL promoter}

When radiolabeled $\mathrm{PR} X$ oligonucleotide was incubated with nuclear extract, DNA-protein complexes were observed as shifted bands. Formation of DNA-protein complex could be prevented by unlabeled $X$ oligonucleotide and C/EBP binding DNA sequence, but not by Sp1 binding sequence (Figure 7C). These suggest that the complexes made by PR X and nuclear protein is specific and the transcription factor involved in this reaction may be $\mathrm{C} /$ EBP family.

The sequence of Box XI are homologous to E-box $P R \quad X I$ has the sequence 'GGCGCCACGTG' that is homologous to the E-box sequence CANNTG or ChoRE sequence CACGTGNNNGCC, reported in the $\mathrm{S} 14$ gene 
A.

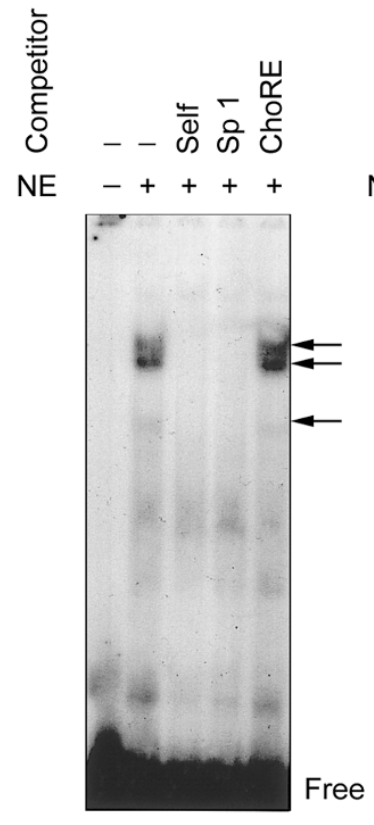

II $(-67 /-41)$

B.
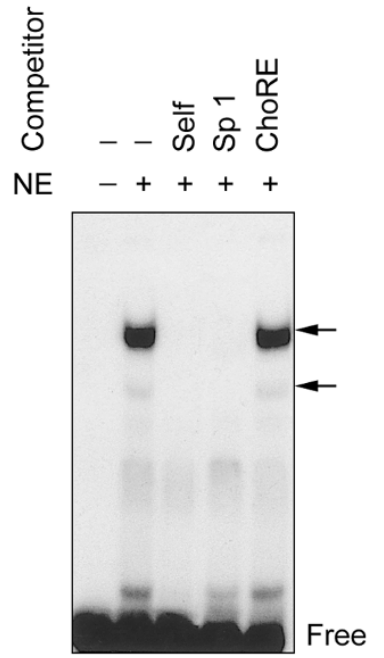

IV $(-142 /-116)$

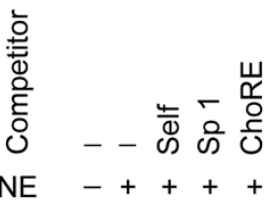

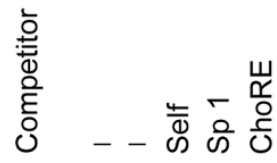

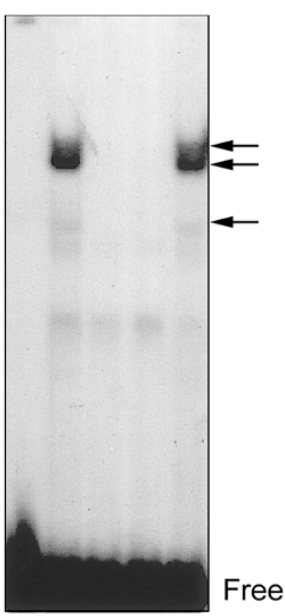

$\mathrm{V}(-165 /-139)$
$\mathrm{NE}-++++$

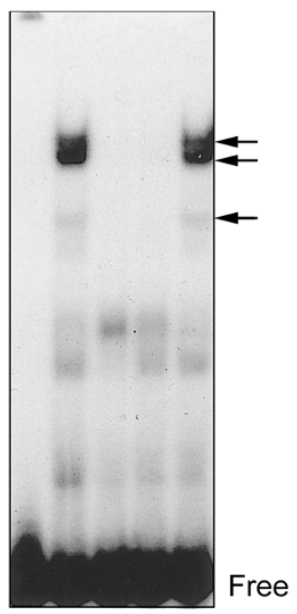

VII (-252/-226)

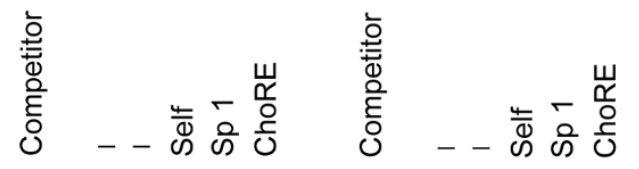

NE

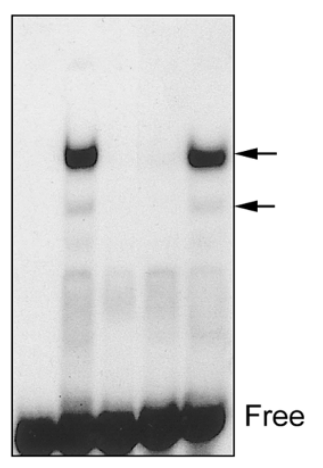

VI (-219/-190)

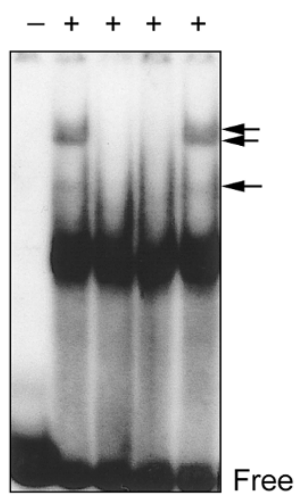

VIII (-349/-325)

Figure 5. Gel mobility shift assay of protected region II, V, VII (A) and IV, VI, VIII (B). Gel mobility shift assays were performed with double stranded ${ }^{32} \mathrm{P}-$ labeled oligonucleotides. The probe was incubated with nuclear extract in the absence or presence of competitors and separated on the $0.25 \mathrm{X}$ TBE, $5 \% \mathrm{glycerol}, 5 \%$ polyacrylamide gel. Competition with molar excess of unlabeled double stranded oligonucleotides is indicated. Shifted bands are indicated.

promoter, in inverted manner. ChoRE of S14 and E-box of L-type pyruvate kinase gene have been reported to induce the transcription by glucose. The induction mechanism of ACL by hormone and refeeding state is similar to those genes. So we examine the possibility that the transcription factor which binds to this element can bind to the PR XI of ACL gene (Figure 7D). Two kinds of shifted bands were observed when the radiolabeled XI oligonucleotide and nuclear extract were incubated. One of them, fast migrating band was disappeared when the cold XI oligonucleotide was added in 100 fold molar excess, but ChoRE oligonucleotide could not compete out the formation of this complex. Slow migrating complexes were competed by both $\mathrm{XI}$ oligonucleotide and ChoRE but a higher molar cold competitor was necessary.

\section{Sp1 transcription factor may be essential for the transcription of ACL gene}

There are six Sp1 binding sites in -419 region of ACL promoter which showed the highest transcription activity on previous report. To determine the function of these Sp1 binding sites, we constructed deletion clones, which carry the various numbers of Sp1 binding site (Figure 8). 

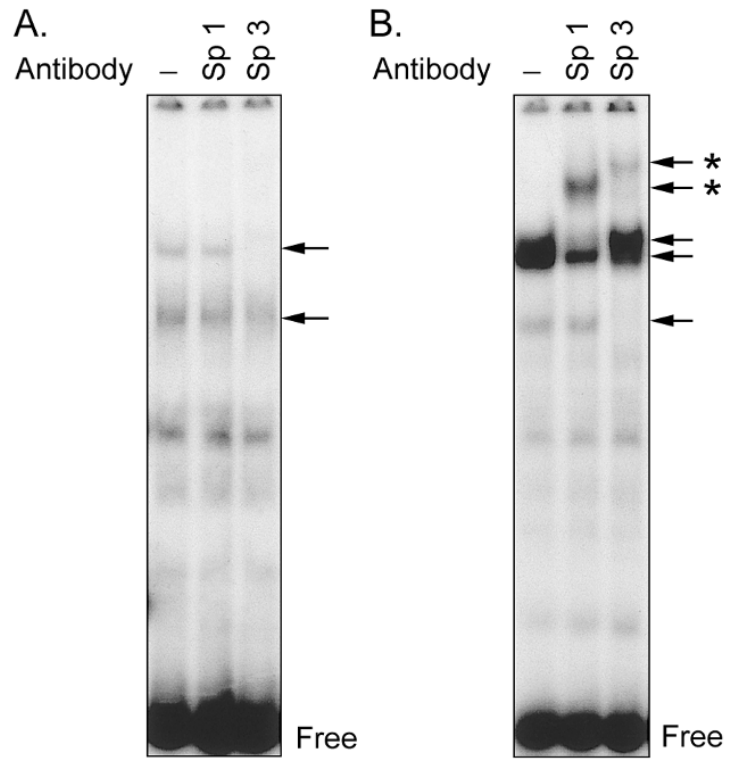

Figure 6. Supershift assay with anti-Sp1 and anti-Sp3 antibodies. Radiolabeled oligonucleotides (protected region II) were incubated with liver nuclear extract prepared from fasted (A) and refed (B) rat under the presence of antibodies against Sp1 and Sp3. Shifted bands and supershifted bands created by Sp1 or Sp3 antibodies (*) are indicated.

ACL promoter -CAT clones were transfected into the primarily cultured rat hepatocyte under $10 \mathrm{mM}$ lactate condition where we intended to detect the basal transcription activity. By removing the region from -625 to -419 , CAT activity was increased by $90 \%$ than that of $p-$ 625-CAT. p-264-CAT, p-218-CAT, in which PR VIII and VII were deleted each, showed almost same level of
CAT activity as that of -419 . $\mathrm{p}$-170-CAT which has three binding sites for Sp1 showed about $60 \%$ of p-419-CAT. And $p-114-C A T$, which has one Sp1 binding site, showed less than $10 \%$ of $p-419-C A T$. These results suggest that PR IX, X, XI in the region from -625 to -419 might have the inhibitory effect to the transcription and six Sp1 binding sites in p-419-CAT construct are involved in regulating $A C L$ promoter activity.

\section{Discussion}

In the liver or adipose tissue of rats, the activities of lipogenic enzymes are known to be regulated by diet or hormones (Katsurada et al., 1990a; Katsurada et al., 1990b; Kim et al., 1992a; Kim et al., 1992b). In the case of $A C L$, its concentration was increased by 20 to 30 folds when the rats were subjected to be fasted and then refed high carbohydrate diet, which was due to the increase in transcriptional activity. To elucidate the transcriptional regulation mechanism of ACL, it is necessary to characterize the ACL promoter. Our previous reports showed that the region from the transcription initiation site to $-419 \mathrm{bp}$ was important for the ACL transcription, and $5^{\prime}$ upstream region from -419 might act as an inhibitor region (Kim et al., 1996). In this study we identified the nuclear protein binding sites, and confirmed the responsible transcription factors.

In the region from transcription start site to $-419 \mathrm{bp}$ region, six Sp1 binding sites (PR II, IV, V, VI, VII and VIII) and CAAT box exist, but TATA box lacks this promoter. In TATA-less promoters, clustered Sp1 sites
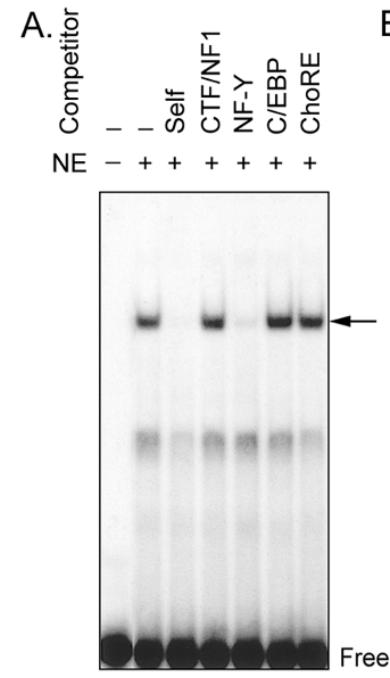

III $(-102 /-72)$
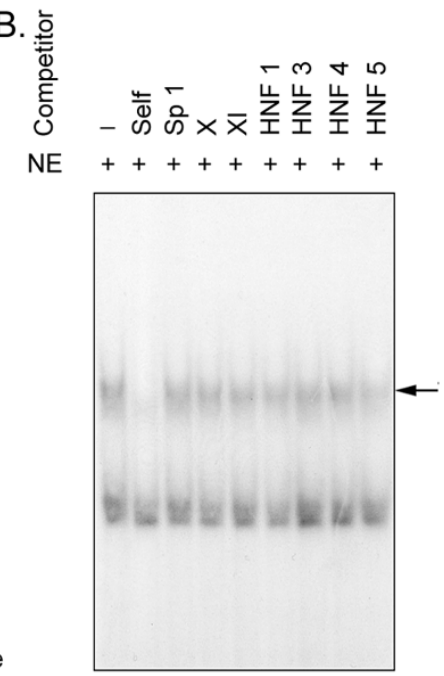

IX (-438/-413)
C.
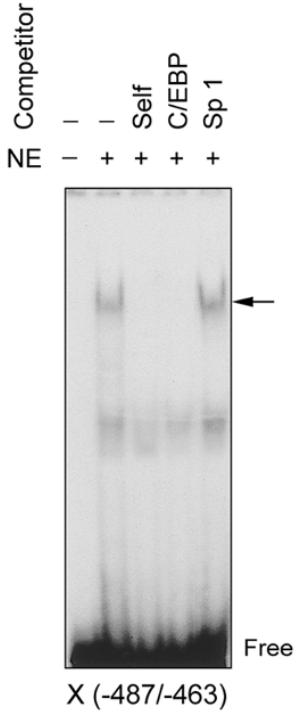

D.
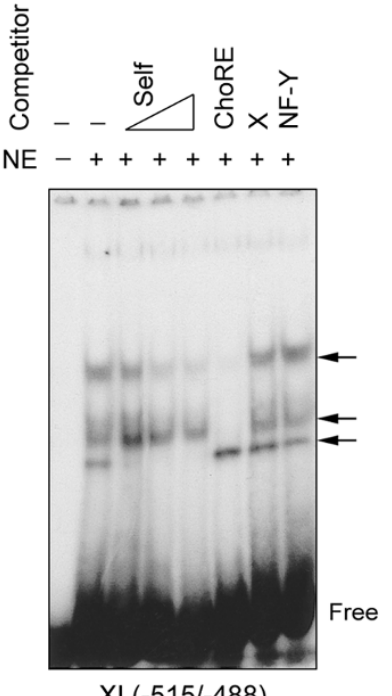

Figure 7. Gel mobility shift assay of protected region III (A), IX (B), X (C), and XI (D). Gel mobility shift assays were performed with double stranded ${ }^{32} \mathrm{P}$-labeled oligonucleotides. The probe was incubated with nuclear extract in the absence or presence of competitors and separated on the $0.25 \mathrm{X}$ TBE, $5 \% \mathrm{glycerol}, 5 \%$ polyacrylamide gel. Competition with 100 fold molar excess (or more) of unlabeled double stranded oligonucleotides is indicated. Sequence-specific shifted bands are indicated. 


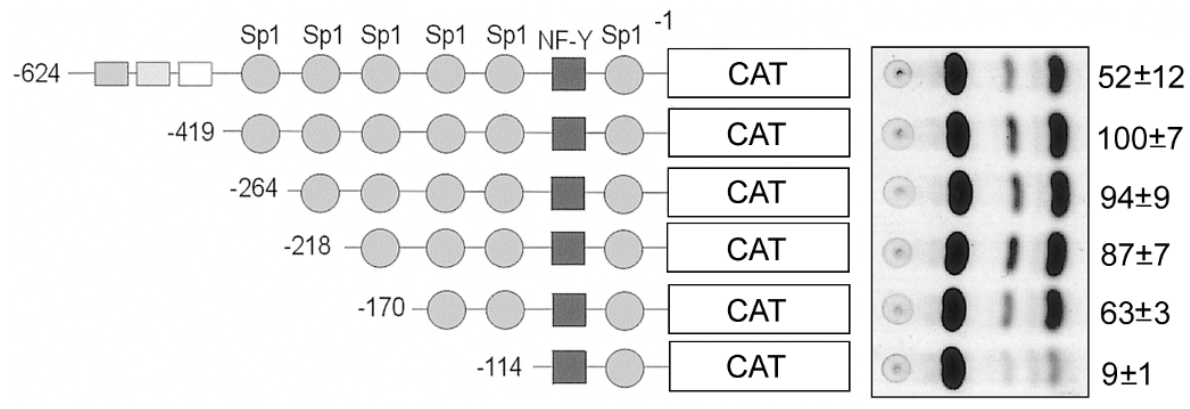

Figure 8. Analysis of the promoter activity of deletion clones containing various numbers of Sp1 sites in primarily cultured rat hepatocytes. Schematic representations of $\mathrm{ACL}$ promoter deletion clones with reporter gene (chloramphenicol acetyltransferase) are shown in left. Each deletion clones were transfected into primarily cultured rat hepatocytes and their CAT activities were determined by thin layer chromatography. The transcription activities of the constructs were denoted as percent of that of $\mathrm{p}-419-\mathrm{CAT}$.

have shown to have the role in transcription start site selection and transcriptional activation (Boisclair et al., 1993; Dusting and Wiginton, 1994; Parks and Shenk, 1996). Like the Sp1 site, the CCAAT box has been found in various promoters and shown to play an essential role in their activity (McKnight and Tjian, 1986). CTF/NF1, C/EBP, and NF-Y have been known to be CCAAT box binding factors. Among these CCAAT box proteins, NF-Y was expected to have a central role in connecting upstream activators with the general transcriptional machinery especially in the absence of TBPTATA interaction in the -25 region.

Among the Sp1 family, Sp3 factor has been known to suppress $\mathrm{Sp} 1$ mediated transcriptional activation by competitively binding to Sp1 consensus elements (Hagen et al., 1994). Besides the role in basal transcription, Sp1 factor was reported to have inducible role in transcription of lipogenic enzyme gene. Glucose treatment to 30A5 preadipocytes could induce the promoter II activation of acetyl CoA carboxylase gene through the increases of Sp1 binding activity because of dephosphorylation of Sp1 (Daniel and Kim, 1996). In present study, we noticed that while Sp1 binding activity in fasted state was low, Sp1 binding was increased in refed state. However, Sp3 binding activity didn't seem to be altered in fasted or refed rats. These results suggest that the ACL transcriptional activity in the induction of $A C L$ transcription by refeeding low fat/high carbohydrate diet may be regulated by Sp1 and/or the ratio of Sp1/Sp3. Further experiments are required to verify this hypothesis. Western blot analysis using nuclear extracts from fasted and refed rats and antibodies against Sp1 and Sp3 factors revealed that the protein amounts of Sp1 and Sp3 in fasted rats and refed rats were the same (data not shown). So the increase of binding activity of Sp1 family in refeeding rats are due to the post-translational modification, for example, phosphorylation or glycosylation of protein. CAT assay with deletion clones and binding assay with nuclear extract of fasted and refed rats suggested that besides the Sp1 factor and NF-Y factor, several factors interacting with the region from -625 to -419 seemed to have roles in regulating both basal and induced transcription. Moreover, refeeding low fat/high carbohydrate diet after fasting brings the increase of blood glucose as well as the alteration of hormonal status in vivo. So, it is also possible that more complex mechanism would be involved. To elucidate the direct factor or the interaction among the various factors involved, further experiments are required.

\section{Acknowledgment}

This study was supported by Yonsei University College of Medicine for Research Instructors' Research Grant 1998-01.

\section{References}

Baker DL, Dave V, Reed T, Periasamy M. Multiple Sp1 binding sites in the cardiac/slow twitch muscle sarcoplasmic reticulum $\mathrm{Ca}^{2+}$-ATPase gene promoter are required for expression in Sol8 muscle cell. J Biol Chem 1996;271:592128

Biosclair YR, Brown AL, Casola S, Rechler MM. Three clustrered $\mathrm{Sp} 1$ sites are required for efficient transcription of the TATA-less promoter of the gene for insuliln-like growth factor-binding protein-2 from the rat. J Biol Chem 1993; 268:24892-901

Bradford MM. A rapid and sensitive method for the quantitation of microgram quantities of protein utilizing the principle of protein-dye binding. Anal Biochem 1976;72:24864

Briggs M, Kadonaga J, Bell S, Tjian R. Purification and biochemical characterization of the promoter-specific transcription. Science 1986;234:47-52

Chodosh LA, Baldwin AS, Carthew RW, Sharp PA. Human CCAAT-binding proteins have heterologous subunits. Cell 1988;53:11-24 
Daniel S, Kim KH. Sp1 mediates glucose activation of the acetyl CoA carboxylase promoter. J. Biol. Chem. 1996;271: 1385-92

Dusting MR, Wiginton DA. Sp1 is essential for both enhancermediated and basal activation of TATA-less human adenosine deaminase promoter. Nucleic Acids Res. 1994;22:669-77

Gorski K, Carneiro M, Schibler U. Tissue-specific in vitro transcription from mouse albumin promoter. Cell 1986;47:76776

Hagen G, Muller S, Beato M, Suske F. Sp1 mediated transcriptional activation is repressed by Sp3. EMBO J. 1994;13:3843-51

Husmann M, Jehnichen P, Jahn B, Schlosshan D, Romahn E. A novel SP-1 site in the human interleukin-1 beta promoter confers preferential transcriptional activity in keratinocytes. Eur J Immun 1996;26:3008-14

Katsurada A, Iritani N, Fukuda H, Matsumura Y, Nishimoto N, Noguchi T, Tanaka T. Effects of nutrients and hormones on transcriptional and post-transcriptional regulation of fatty acid synthase in rat liver. Eur J Biochem 1990a;190:427-33

Katsurada A, Iritani N, Fukuda H, Matsumura Y, Nishimoto N, Noguchi T, Tanaka T. Effects of nutrients and hormones on transcriptional and post-transcriptional regulation of acetyl CoA carboxylase in rat liver. Eur J Biochem 1990b;190:435-41

Kim KS, Kang JG, Moon YA, Park SW, Kim YS. Regulation of ATP-citrate lyase gene transcription. Yonsei Med J 1996;37: 214-24

Kim KS, Park SW, Kim YS. Regulation of ATP-citrate lyase at transcriptional and post-transcriptional levels in rat liver. Biochem Biophys Res Commun 1992a;189:264-71

Kim KS, Park SW, Kim YS. Regulation of fatty acid synthase at transcriptional and post-transcriptional levels in rat liver. Yonsei Med J 1992b;33:199-208

Kim KS, Park SW, Moon YA, Kim YS. Organization of the $5^{\prime}$ flanking region of the rat ATP-citrate lyase gene. Biochem $\mathrm{J}$
$1994 ; 302: 759-64$

Kornacker MS, Lowenstein JM. Citrate and conversion of carbohydrate into fat. Biochem J 1965;95:832-37

Mantovani R. A survey of 178 NF-Y binding CCAAT boxes. Nucleic Acids Res 1998;26:1135-43

McKnight S, Tjian R. Transcriptional selectivity of viral genes in mammalian cell. Cell 1986;46:795-805

Liu Z, Towle HC. Functional synergism in the carbohydrateinduced activation of liver type pyruvate kinase gene expression. Biochem J 1995;308:105-11

Moon YA, Kim KS, Cho UH, Yoon DJ, Park SW. Characterization of regulatory elements on the promoter region of human ATP citrate-lyase. Exp Mol Med 1999;31:108-14

Moon YA, Kim KS, Park SW, Kim YS. Cloning and identification of exon-intron organization of the rat ATP-citrate lyase. Biochim Biophys Acta 1996;1307:280-84

Moon YA, Lee JJ, Park SW, Ahn YH, Kim KS. The roles of sterol regulatory element-binding proteins in the transactivation of the rat ATP-citratelyase promoter. J Biol Chem 2000;275:30280-86

Parks CL, Shenk T. The serotonin 1a receptor gene contains a TATA-less promoter that responds to MAZ and Sp1. J Biol Chem 1996;271:4417-30

Rajmondjean M, Cereghini C, Yaniv M. Several distinct CCAAT box binding proteins coexist in eukaryotic cells. Proc Natl Aca Sci USA 1988;85:757-61

Sambrook J, Fritsch EF, Maniatis T. (1989) Molecular Cloning: A Laboratory Manual, 2nd Ed. Cold Spring Harbor Press, Cold Spring Harbor

Shih H, Towle HC. Definition of the carbohydrate response element of the rat S14 gene. Evidence for a common factor required for carbohydrate regulation of hepatic gene. J Biol Chem 1992;267:13222-28 